\title{
Pattern of Congenital Heart Disease in Children Admitted into Tertiary Care Hospitals of Sylhet: A Multicenter Study
}

\author{
MUJIBUL HOQUE ${ }^{1}$, MD. MUAZZEM HUSSAIN², AT REZAAHMAD ${ }^{3}$, MD. SHAHAB UDDIN ${ }^{4}$
}

\begin{abstract}
Objective: This study was carried out to find out the prevalence of CHD and their type among Children attended in the inpatient and out patient department of district tertiary care hospital of Sylhet.

Methodology: This prospective cross sectional study was carried out in the department of Paediatrics of 4 medical college hospitals of Sylhet over a period of 1 year from January 2012 to December 2012. All children with the confirmed diagnosis of $C H D$ with the age ranging from $1^{\text {st }}$ day of life to 12 years were analyzed considering the pattern of $C H D$.

Results: A total of 234 cases of CHD were admitted. Maximum cases of CHD were admitted between 29 days to 1year age group and 148 (63.25\%) were male and the rest $86(36.75 \%)$ were female. The male-female ration was 1.72:1. Most of the CHD (65.38\%) were acyanotic and $34.42 \%$ cases were cyanotic. The commonest CHD was found VSD (33.33\%) which was followed by ASD (16.24\%), TOF(11.54\%), Complex CHD (11.54\%) and PDA (10.68\%).

Conclusion: It was concluded from this study that the male children are mostly sufferer from CHD and acyanotic heart disease was commonest type of CHD.
\end{abstract}

Key words: Pattern, Congenital heart disease, Sylhet.

\section{Introduction:}

Congenital heart diseases (CHD) are structural problems that arise from abnormal formation of the heart or major blood vessels. ${ }^{1}$ It is the most common congenital anomaly and also the commonest type of heart disease in children. ${ }^{2}$ If left untreated, $\mathrm{CHD}$ is an important cause of mortality in children, so early detection and proper intervention is especially important. It also causes a tremendous psychological stress and economic burden to the family and country. The estimated incidence of CHD is 9 per 1,000 live births which correspond to 1.35 million newborns with CHD every year, representing a major global health

1. Assistant Professor, Department of Paediatrics, Sylhet M.A.G. Osmani Medical College, Sylhet.

2. Registrar, Department of Paediatrics, Jalalabad Ragib-Rabeya Medical College Hospital, Sylhet.

3. Associate Professor, Department of Paediatrics, North East Medical College, Sylhet

4. Assistant Professor, Department of Paediatrics, Sylhet Women's Medical College, Sylhet

Correspondence: Dr. Mujibul Hoque, Assistant Professor, Department of Paediatrics, Sylhet M.A.G. Osmani Medical College, Sylhet, Mobile no: 01911-132026, E-mail: drmujib@ymail.com burden. ${ }^{3}$ The prevalence of $\mathrm{CHD}$ in India is 8.54 per 1000 live birth; ${ }^{4}$ in Pakistani population is 11 per 1000 live birth $^{5}$. Congenital heart defects are the most common type of birth defect in the United States, affecting nearly $1 \%$ of-or about 40,000 - births per year. ${ }^{6}$ In Europe the average total prevalence of CHD was 8.0 per 1000 births, and live birth prevalence was 7.2 per 1000 births. $^{2}$ There is no nationwide survey to see the prevalence of $\mathrm{CHD}$ in Bangladesh. A hospitalbased study at Dhaka reported the incidence of $\mathrm{CHD}$ is $25 / 1000$ live birth ${ }^{7}$. Pattern of CHD varies from country to country, region to region. In developed countries pattern of $\mathrm{CHD}$ is well documented. There is no such nationwide data in Bangladesh. A multicenter study in Dhaka found ventricular septal defect (VSD), atrial septal defect (ASD), patent ductus arteriosus (PDA), Tetralogy of Fallot (TOF), transposition of great arteries (TGA), pulmonary stenosis (PS) and A-V canal defect as common congenital heart diseases in Bangladesh. ${ }^{8}$

Sylhet is a peripheral divisional city. There are one government and 3 private medical college hospitals in 
Sylhet having tertiary care facility. Almost all children with CHD from Sylhet division visit at least one of these medical college hospitals. So, data from these 4 hospitals might be represent the whole Sylhet division. Though some studies are done in Dhaka to see the pattern of CHD, no such study is done in Sylhet. This study was done to find out the pattern of CHD among the admitted children in 4 medical college hospitals of Sylhet.

\section{Methodology}

This prospective cross sectional study was carried out in the department of pediatrics of 4 medical college hospitals of Sylhet, namely Sylhet MAG Osmani Medical College Hospital (SOMCH), Jalalabad RagibRabeya Medical College Hospital (JRRMCH), North East Medical College Hospital (NEMCH) and Sylhet Women's Medical College Hospital (SWMCH) over a period of 1 year from January 2012 to December 2012. All admitted children with CHD were enrolled in the study. The study cases were selected purposively; all children with the confirmed diagnosis of $\mathrm{CHD}$ with the age ranging from $1^{\text {st }}$ day of life to 12 years were included in the study. Acquired heart diseases such as rheumatic heart disease or mitral valve prolapse were excluded. The diagnosis was confirmed by color Doppler echocardiography done by qualified cardiologist. CHD with multiple lesions which could not be diagnosed as a single entity were termed as complex CHD. Ethical issues were addressed duly.

\section{Results:}

During the study period a total number of 234 cases were admitted with $\mathrm{CHD}$ and among them; 148 in $\mathrm{SOMCH}, 54$ in JRRMCH, 12 in NEMCH \& 20 in SWMCH. Maximum cases of CHD were admitted in 29 days to 1year age group in all 4 institutes with a total of 140 (59.83\%). Age distribution of CHD patients are shown in table-l. Among 234 patients 148 (63.25\%) were male and the rest $86(36.75 \%)$ were female with a male-female ratio 1.72:1(figure-I).

Among the children with CHD 65.38\% (153/234) were acyanotic and 34.42\% (81/234) were cyanotic CHD. In SOMCH 90 (60.81\%) were acyanotic and 58 (39.19\%) were cyanotic. The distribution of acyanotic and cyanotic CHD is shown in figure - II.

The commonest CHD was VSD (33.33\%) which was followed by ASD (16.24\%), TOF (11.54\%), Complex CHD (11.54\%) and PDA (10.68\%). Among 78 cases of VSD 42 (28.38\%) were in SOMCH, 25 (46.30\%) in JRRMCH, 4 (33.33\%) in NEMCH and 7(35.00\%) in SWMCH. Pattern of CHD in 4 hospitals are shown in Table-II.

Table I

Distribution of Age in CHD patients $(n=234)$

\begin{tabular}{lccccc}
\hline & SOMCH & JRRMCH & NEMCH & SWMCH & Total \\
\hline 0-28 Days & $10(6.76 \%)$ & $14(25.93 \%)$ & $2(16.67 \%)$ & $1(5 \%)$ & $27(11.54 \%)$ \\
29 days - 1year & $92(62.16 \%)$ & $30(55.56 \%)$ & $7(58.33 \%)$ & $11(55 \%)$ & $140(59.83 \%)$ \\
Over 1year - 5 years & $26(17.57 \%)$ & $7(12.96 \%)$ & $2(16.67 \%)$ & $6(30 \%)$ & $41(17.52 \%)$ \\
Over 5 years & $20(13.51 \%)$ & $3(5.56 \%)$ & $1(8.33 \%)$ & $2(10 \%)$ & $26(11.11 \%)$ \\
\hline Total & 148 & 54 & 12 & 20 & 234 \\
\hline
\end{tabular}

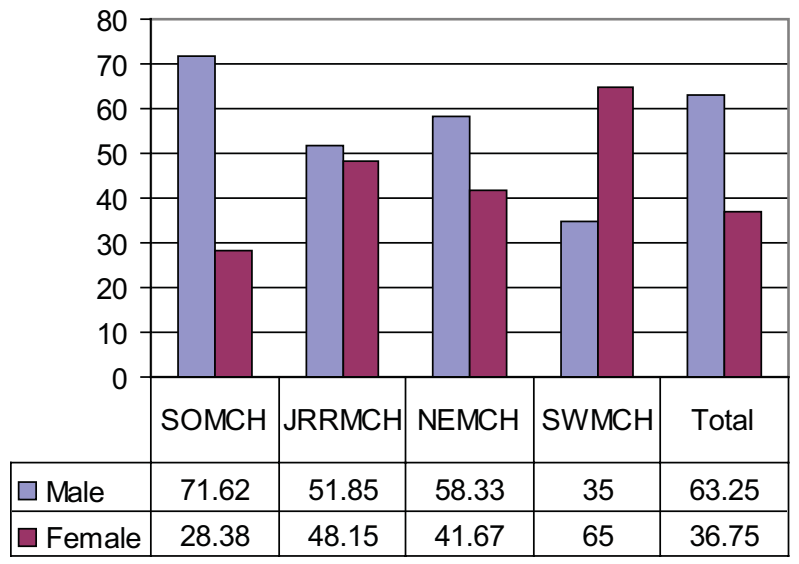

Fig.-1: Distribution of sex in CHD patients

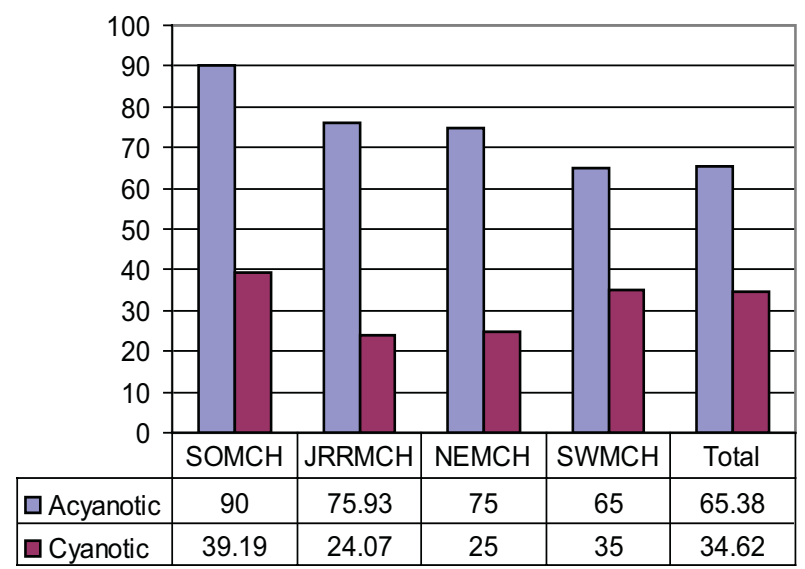

Fig.-2: Distribution of Acyanotic \& Cyanotic CHD 
Table II

Pattern of CHD in Four Hospitals ( $n=234)$

\begin{tabular}{lccccc}
\hline & SOMCH & JRRMCH & NEMCH & SWMCH & Total \\
\hline VSD & $42(28.38 \%)$ & $25(46.30 \%)$ & $4(33.33 \%)$ & $7(35.00 \%)$ & $78(33.33 \%)$ \\
ASD & $24(16.22 \%)$ & $7(12.96 \%)$ & $3(25.00 \%)$ & $4(20.00 \%)$ & $38(16.24 \%)$ \\
TOF & $21(14.19 \%)$ & $4(7.41 \%)$ & $1(8.33 \%)$ & $1(5.00 \%)$ & $27(11.54 \%)$ \\
PDA & $16(10.81 \%)$ & $5(9.26 \%)$ & $2(16.67 \%)$ & $2(10.00 \%)$ & $25(10.68 \%)$ \\
TGA & $12(8.11 \%)$ & $1(1.85 \%)$ & $0(0.00 \%)$ & $2(10.00 \%)$ & $15(6.41 \%)$ \\
TAPVR & $6(4.05 \%)$ & $0(0.00 \%)$ & $0(0.00 \%)$ & $0(0.00 \%)$ & $6(2.56 \%)$ \\
PS & $4(2.70 \%)$ & $0(0.00 \%)$ & $0(0.00 \%)$ & $0(0.00 \%)$ & $4(1.71 \%)$ \\
AV Canal Defect & $3(2.03 \%)$ & $0(0.00 \% 0$ & $0(0.00 \%)$ & $1(5.00 \%)$ & $4(1.71 \%)$ \\
DORV & $2(1.35 \%)$ & $0(0.00 \%)$ & $0(0.00 \%)$ & $0(0.00 \%)$ & $2(0.85 \%)$ \\
CoA & $2(1.35 \%)$ & $0(0.00 \%)$ & $0(0.00 \%)$ & $0(0.00 \%)$ & $2(0.85 \%)$ \\
MR & $0(0.00 \%)$ & $2(3.70 \%)$ & $0(0.00 \%)$ & $0(0.00 \%)$ & $2(0.85 \%)$ \\
AS & $1(0.68 \%)$ & $0(0.00 \%)$ & $0(0.00 \%)$ & $0(0.00 \%)$ & $1(0.43 \%)$ \\
AR & $0(0.00 \%)$ & $1(1.85 \%)$ & $0(0.00 \%)$ & $0(0.00 \%)$ & $1(0.43 \%)$ \\
TA & $1(0.68 \%)$ & $0(0.00 \%)$ & $0(0.00 \%)$ & $0(0.00 \%)$ & $1(0.43 \%)$ \\
TR & $0(0.00 \%)$ & $1(1.85 \%)$ & $0(0.00 \%)$ & $0(0.00 \%)$ & $1(0.43 \%)$ \\
Complex CHD & $14(9.46 \%)$ & $8(14.81 \%)$ & $2(16.67 \%)$ & $3(15.00 \%)$ & $27(11.54 \%)$ \\
\hline Total & 148 & 54 & 12 & 20 & 234 \\
\hline
\end{tabular}

\section{Discussion:}

In the present study most of the CHD patients (59.83\%) were diagnosed at 29 days -1 year age group. Hussain et al ${ }^{8}$ found the same age distribution in their multicenter study. About $56.84 \%$ patients in BSMMU, 44.99\% in NICVD, 45.25\% in CMH and $39.19 \%$ in DSH belongs to the same age group. ${ }^{8}$ Hussain et $\mathrm{al}^{9}$ in another study in Dhaka Shishu Hospital found that $56.60 \%$ CHD patients belonged to the same age group in 1999 and 36.40\% in 2009. The distribution of age varied in different institutes in the above mentioned studies which also varied among the patients of 4 institutes in the present study.

In the current study, male patients outnumbered female patients with male-female ratio 1.7:1. Hussain et al ${ }^{8}$ found male-female ratio 1.98:1in DSH, 1.39:1 in CMH, 2.55:1 in NICVD and 1.24:1 in BSMMU which are similar to our study. A study in Rajshahi Medical College Hospital ${ }^{10}$ found male-female ratio 1.3:1. The difference in male female ratio in different institutions may be due to regional variations.

Acyanotic CHD was more common in the present study $(65.38 \%)$. Hussain et $\mathrm{l}^{8}$ found similar finding in DSH, CMH, NICVD \& BSMMU. Sharmin et al ${ }^{10}$ also found similar result in Rajshahi Medical College Hospital.

In the current study VSD was the commonest CHD (33.33\%) which was followed by ASD, TOF, Complex $\mathrm{CHD}$ and PDA. This finding is almost similar to the findings of Hussain et $\mathrm{al}^{8}$ and Sharmin et $\mathrm{al}^{10}$. The commonest cyanotic CHD was TOF (11.54\%) in this study. Studies of Hussain et $\mathrm{al}^{8}$, Sharmin et $\mathrm{al}^{10}$ and Rahman et al ${ }^{11}$ support this finding. Complex CHD comprises a large amount (11.54\%) in the present study. Sharmin et $\mathrm{al}^{8}$ reported $7 \%$ multiple lesion in their study. But no such finding is mentioned in the study of Hussain et $\mathrm{al}^{9}$ and Rahman et al ${ }^{11}$. This large number of Complex CHD may result from less expertise of the cardiologists who performed echocardiography. It is noteworthy that there is no pediatric cardiologist in Sylhet and all echocardiography of the present study were done by adult cardiologists.

\section{Conclusion:}

VSD was the commonest CHD in Sylhet which was followed by ASD, TOF and PDA. A community based 
survey should be carried out to assess the definite prevalence and pattern of CHD in Sylhet.

\section{References:}

1. American Heart Association. Statistical Fact Sheet 2013 Update. Congenital Cardiovascular Defects. Available at: http://www.heart.org/idc/ groups/heart-public/@wcm/@sop/@smd/ documents/downloadable/ucm_319830.pdf, accessed on June 01, 2013.

2. Dolk H, Loane M, Garne E. European Surveillance of Congenital Anomalies (EUROCAT) Working Group Congenital heart defects in Europe: prevalence and perinatal mortality, 2000 to 2005. Circulation 2011; 123:841-49.

3. Linde DV, Konings EEM, Slager MA, Witsenburg M, Helbing WA, Takkenberg JJM, RoosHesselink JW. Birth Prevalence of Congenital Heart Disease Worldwide: A Systemic Review and Meta-analysis. J Am Coll Cardiol 2011; 58:2241-47.

4. Bhat NK, Dhar M, Kumar R, Patel A, Rawat A, Kalra BP. Prevalence and Pattern of Congenital Heart Disease in Uttarkhand, India. Indian J Pediatr 2013; 80:281-85.

5. Agadoorappa P, Oddie S, Pawson N, Sheridon E. Do pakistani babies have more congenital heart defects? Preliminary findings from our birth cohort study. Arch Dis Child 2011; 96: A35. doi10.1136/adc,2011.21256376.

6. Reller MD, Strickland MJ, Riehle-Colarusso T, Mahle WT, Correa A. Prevalence of congenital heart defects in Atlanta, 1998-2005. J Pediatrics 2008; 153:807-13.

7. Fatema NN, Chowdhury RB, Chowdhury L. Incidence of Congenital Heart Disease among Hospital Live Birth in a Tertiary Hospital of Bangladesh. CVJ 2008; 1:14-20.

8. Hussain M, Tahura S, Hussain MZ, Fatema NN, Razzaque SKA. Pattern of Congenital Heart Disease in Bangladesh: A Multi-center Study. Ds (Child) H J 2011; 27:5-11.

9. Hussain M, Tahura S, Sayeed AB, Rahman MM, Rahman M, Kar SK. Past and Present Pattern of Congenital Heart Disease at Dhaka Shishu Hospital: A Situation Analysis. Bangladesh J Child Health 2010; 34:51-55.

10. Sharmin LS. Haque MA, Bari MI, Ali MA. Pattern and Clinical Profile of Congenital Heart Disease in a Teaching Hospital. TAJ 2008; 21:58-62.

11. Rahman F, Salman M, Akhter N, Patwary SR, Anam K, Rahman MM, et al. Pattern of Congenital Heart Diseases. Mymensingh Med J 2012; 21:246-50. 